\title{
Progress in experimental and clinical subpulmonary assistance for Fontan circulation
}

\author{
Christopher R. Broda, MD, ${ }^{\mathrm{a}}$ Doris A. Taylor, $\mathrm{PhD},{ }^{\mathrm{b}}$ and Iki Adachi, $\mathrm{MD}$
}

\author{
From the Departments of ${ }^{\mathrm{a} P e d i a t r i c}$ Cardiology and ${ }^{\mathrm{c}}$ Congenital Heart Surgery, Baylor College of Medicine/ \\ Texas Children's Hospital, Houston, Tex; ${ }^{\mathrm{b}}$ Regenerative Medicine Research, Texas Heart Institute, Houston, \\ Tex. \\ Received for publication Dec 19, 2017; revisions received April 9, 2018; accepted for publication April 24, 2018; \\ available ahead of print June 5, 2018. \\ Address for reprints: Christopher R. Broda, MD, Department of Pediatric Cardiology, Texas Children's Hospital, \\ 6621 Fannin St, MC 19345C, Houston, TX 77030 (E-mail: broda@bcm.edu). \\ J Thorac Cardiovasc Surg 2018;156:1949-56 \\ $0022-5223 / \$ 36.00$ \\ Copyright (C) 2018 by The American Association for Thoracic Surgery \\ https://doi.org/10.1016/j.jtcvs.2018.04.102
}

Video clip is available online.

The Fontan operation was described in 1971 by Fontan and Baudet $^{1}$ to palliate tricuspid atresia. The physiology of this anatomic reconfiguration relies on postcapillary energy and a favorable pulmonary-atrial pressure gradient to drive venous blood return to the heart. Completion of Fontan circulation fundamentally alters the cardiopulmonary physiology. ${ }^{2}$ Although saturations are normalized, disadvantages include increased systemic venous pressure, venous congestion, and decreased cardiac output (CO). It is estimated that approximately 50,000 to 70,000 individuals have received Fontan circulation completion ${ }^{3}$; this patient population is expected to double over the next 20 years. ${ }^{4}$ Many patients experience complications related to the aforementioned deranged hemodynamics that are unavoidable after bypass of the subpulmonary ventricle. ${ }^{5}$ Generally, these issues develop over time and continue to worsen, resulting in a "failing Fontan" physiology, ${ }^{6-8}$ which has a high incidence of mortality. ${ }^{9-11}$ The growing and aging Fontan population is likely to have high rates of medical resource use ${ }^{12,13}$ and will likely place increased pressure on already burdened organ transplantation programs. ${ }^{14}$

In their original description, Fontan and Baudet ${ }^{1}$ intended to use the contractile properties of the right atrium (RA) to propel blood to the lungs. A valve was placed at the atriopulmonary anastomosis to optimize "ventriculized" atrial work and prevent retrograde flow. Early experience with valves within the Fontan circulation was associated with obstruction to flow and thrombosis. ${ }^{15}$ Attempts to use the atrium as a pumping chamber were abandoned because of poor results and a high incidence of

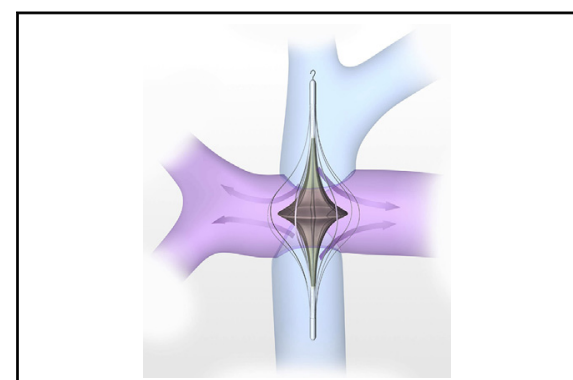

Experimental subpulmonary assist device for Fontan circulation: von Karman impeller pump.

\section{Central Message}

Patients with Fontan circulation experience sequelae related to chronic attrition from altered hemodynamics; a subpulmonary assist device may improve cardiovascular status and alleviate symptoms.

\section{Perspective}

Investigators have formulated creative solutions to address the unmet need for subpulmonary Fontan circulation assistance, but substantial clinical translation has not been realized. In this article, we review experimental and clinical attempts for cavopulmonary assistance in patients with single ventricles and highlight promising strategies to create a subpulmonary assist device for the Fontan circulation.

See Editorial Commentary page 1957.

See Editorial page 1947.

reoperations. ${ }^{16}$ There are significant energy losses as the blood traverses the complex geometric shape of the atrium. ${ }^{17}$ Further, in vitro studies demonstrated pulsation of valveless chambers provide net resistance to prograde flow. Because of this, surgeons currently "streamline" flows between inferior vena cava (IVC) and pulmonary arteries (PAs), creating a total cavopulmonary connection (TCPC) by the lateral tunnel operation or using an extracardiac conduit that excludes most or all of the atrium. . $^{5,16}$

Today, clinical therapies available to improve Fontan hemodynamics are limited. Addressing "right-sided" failure is a significant unmet need because approximately two thirds of adult patients with Fontan circulation who die or require heart transplantation have preserved single- 


$$
\begin{aligned}
& \text { Abbreviations and Acronyms } \\
& \text { CO }=\text { cardiac output } \\
& \text { CVP }=\text { central venous pressure } \\
& \text { ePTFE }=\text { expanded polytetrafluoroethylene } \\
& \text { IVC }=\text { inferior vena cava } \\
& \text { LD }=\text { latissimus dorsi } \\
& \text { MPA }=\text { main pulmonary artery } \\
& \text { PA }=\text { pulmonary artery } \\
& \text { RA }=\text { right atrium } \\
& \text { SMV }=\text { skeletal muscle ventricle } \\
& \text { SVC }=\text { superior vena cava } \\
& \text { TCPC }=\text { total cavopulmonary connection } \\
& \text { TERM }=\text { tissue engineering/regenerative medicine } \\
& \text { VAD }=\text { ventricular assist device }
\end{aligned}
$$

ventricle systolic function. ${ }^{18} \mathrm{~A}$ long-standing interest is recapitulating the subpulmonary ventricle effect in patients palliated to Fontan circulation to increase pulmonary blood flow and decrease central venous pressure (CVP) (Video 1). Multiple investigators have attempted subpulmonary support using biological or mechanical assists (Figure 1).

\section{BIOLOGICALLY BASED FONTAN CIRCULATION ASSISTS}

Methods to provide Fontan circulation assistance with biologic devices can be organized within 2 major categories that include use of autologous skeletal muscle to create an independent "neoventricle" or a "wrap" for external compression (Figure 2). Both methods take advantage of the contractile properties of skeletal muscle to generate a compressive force to pump blood into the pulmonary circuit.

In the 1980s, several groups attempted to assist pulmonary blood flow in the Fontan circulation by using autologous latissimus dorsi (LD). In 1987, Macoviak and colleagues $^{21}$ described use of LD for myoventriculoplasty, creating a neoventricle myograft to establish pulmonary blood flow in a dog model. Building on this concept, skeletal muscle ventricles (SMVs) were constructed from LD in dogs. ${ }^{19,22}$ The SMV received systemic venous return from the IVC and superior vena cava (SVC), and the outflow was connected to the main pulmonary artery (MPA); valves were incorporated to promote unidirectional flow. A pacing system stimulated the SMV to contract. After the SMV was turned "on", it generated pulsatile flow of greater than $5 \mathrm{~L} / \mathrm{min}$ to the PAs. However, the SMVs were less compliant than ventricular myocardium, and the inflow valve posed an impediment to flow. The authors asserted that an alternative design was needed to overcome hampered SMV preload, and Niinami and colleagues ${ }^{23}$ devised a right ventricle assist using a "Rastelli-SMV" configuration where an SMV was
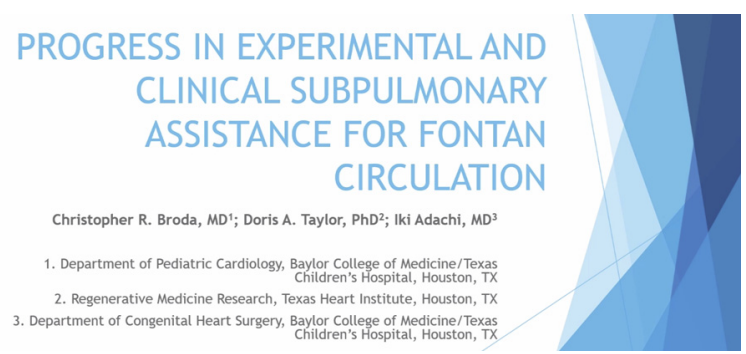

VIDEO 1. A detailed summary of the article in slide show format is narrated by Chris Broda, MD. Video available at: https://www.jtcvs.org/ article/S0022-5223(18)31241-8/fulltext.

placed between the right ventricle and MPA. This resulted in significantly increased $\mathrm{CO}$, peak pulmonary arterial pressures, and systemic SBP with some animals surviving more than 3 months. ${ }^{24}$ The "Rastelli-SMV" model facilitated filling of the SMV with right ventricular work, but this configuration is not applicable for Fontan circulation assistance.

Atrial cardiomyoplasty was investigated as a potential method to increase pulmonary flows in the Fontan circulation. ${ }^{20,25-27}$ In a canine model, atrial cardiomyoplasty was used to increase pulmonary blood flow by "ventricularization" of the RA. ${ }^{20}$ A modified atriopulmonary Fontan connection was created by surgical closure of the tricuspid valve and placement of a conduit between the RA appendage and the distal PA trunk. The left LD was mobilized and wrapped around the RA conduit and stimulated to produce pulsatile, augmented pulmonary flow. Investigators showed a concomitant increase in CVP and postulated a valve (at inferior cavoatrial junction) was needed to produce meaningful work. In a similar experiment in which an expanded polytetrafluoroethylene (ePTFE) conduit was compressed by LD, investigators found a decrease in total pulmonary flow due to impaired conduit filling. The results from these experiments precluded clinical translation of these subpulmonary assist strategies.

Enthusiasm for using autologous skeletal muscle to provide a physiologic, pulsatile correction to the Fontan circulation waned. Use of autologous LD has an associated implicit morbidity, and overstimulation of skeletal muscle with electrical current leads to muscle injury. ${ }^{28}$ Harmful effects are seen with rapid stimulation; biopsies from the muscle wraps demonstrate fibrofatty replacement of contractile tissue. ${ }^{29}$ In addition, "normal" systemic venous pressures were unable to provide adequate preload to the constructs. ${ }^{22,25}$

\section{MECHANICALLY BASED FONTAN CIRCULATION ASSIST}

Given the revolutionary impact of mechanical support devices in the treatment and care of those with heart failure, ${ }^{30-32}$ investigators moved away from biologically derived 


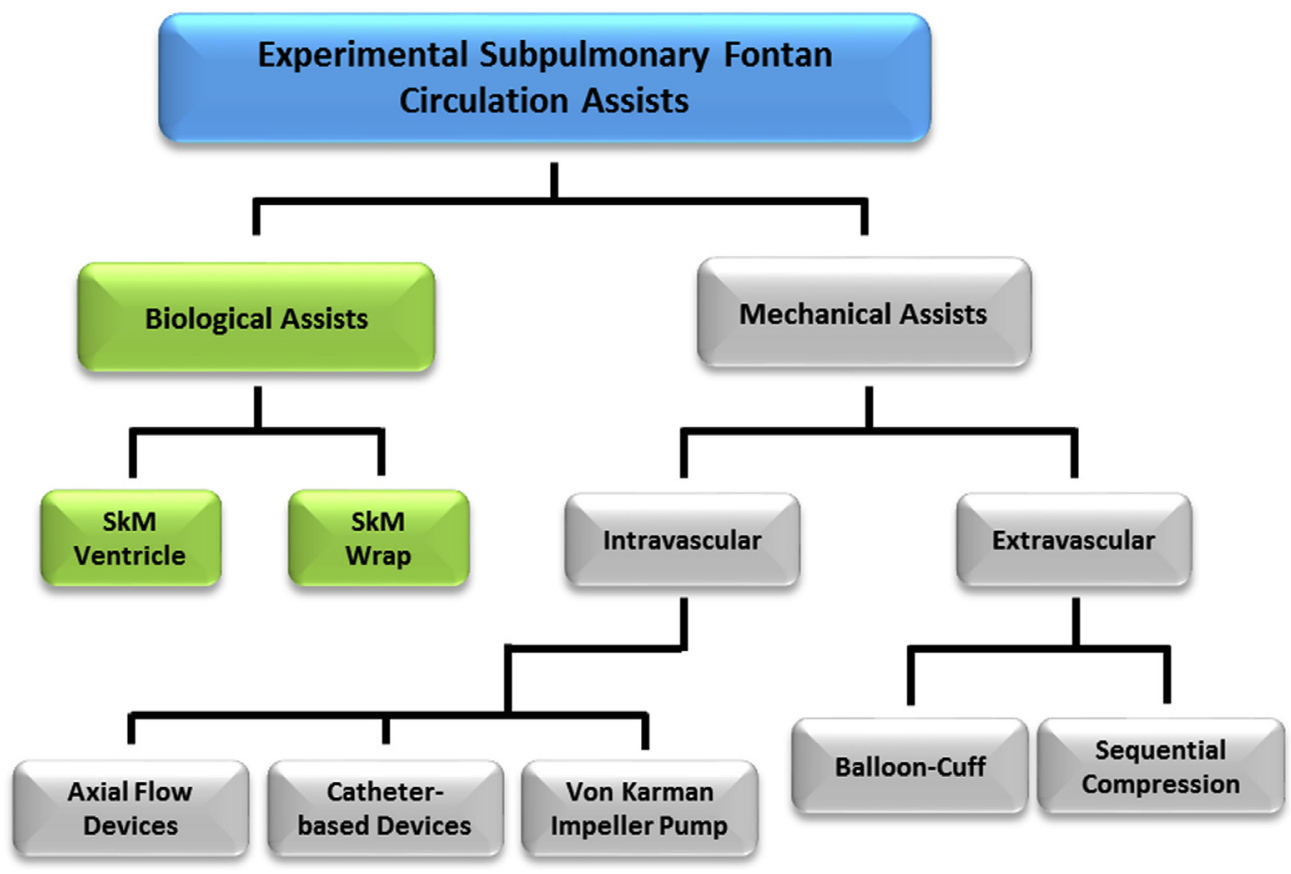

FIGURE 1. Subpulmonary Fontan assistance strategies. Biological assists have been primarily composed of autologous skeletal muscle-based ventricles or wraps. Mechanical assist strategies can be categorized between intravascular and extravascular-based devices. Intravascular assists include axial flow devices, catheter-based assist devices, and von Karman impeller pump. Extravascular assists consist of balloon-cuff or sequential "peristaltic" compression scenarios. SkM, Skeletal muscle.

solutions for the Fontan circulation assistance and have instead focused on mechanical devices to provide for Fontan circulation assistance. In a seminal article, Rodefeld and colleagues ${ }^{33}$ described the use of 2 axial flow pumps to provide pulmonary blood flow in a sheep model of TCPC (Figure 3). The SVC and IVC were anastomosed to the PA under cardiopulmonary bypass, and axial flow pumps were advanced in the IVC and SVC. Cavopulmonary support was titrated to obtain nearly normal physiologic parameters including mean systemic venous and PA pressures; mechanical support of the simulated TCPC circulation provided stable cardiopulmonary function throughout the duration of the experiments. To prevent recirculation and retrograde flow, an obstructive separator was needed to isolate the inflow from the outflow of the pumps. Additional concerns were raised about caval collapse from device suction.

Studies followed using computationally modeled simulations of mechanical cavopulmonary assistance. Investigators demonstrated feasibility of "virtual" flow assist
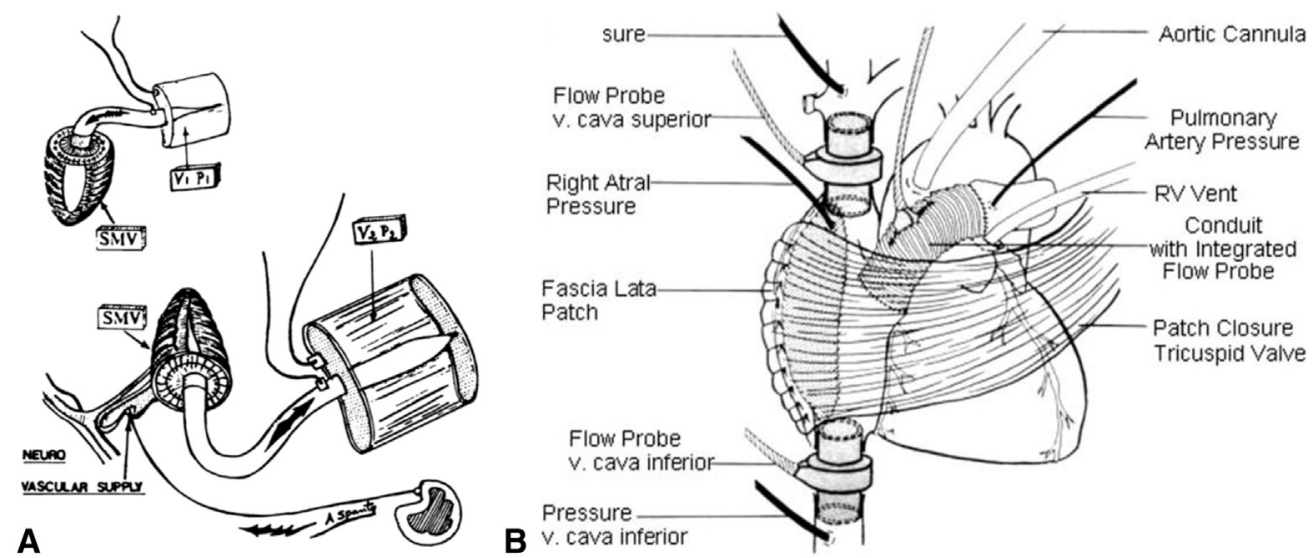

FIGURE 2. Biological Fontan assists. A, Skeletal muscle ventricle fashioned from LD connected to a mock circulation device ${ }^{19}$ (permission for reprint obtained from Wolters Kluwer Health, Inc). B, Skeletal muscle wrap is placed around the atrium in an atriopulmonary Fontan connection scenario ${ }^{20}$ (permission for reprint obtained from Oxford University Press). $S M V$, Skeletal muscle ventricle; $R V$, right ventricle. 

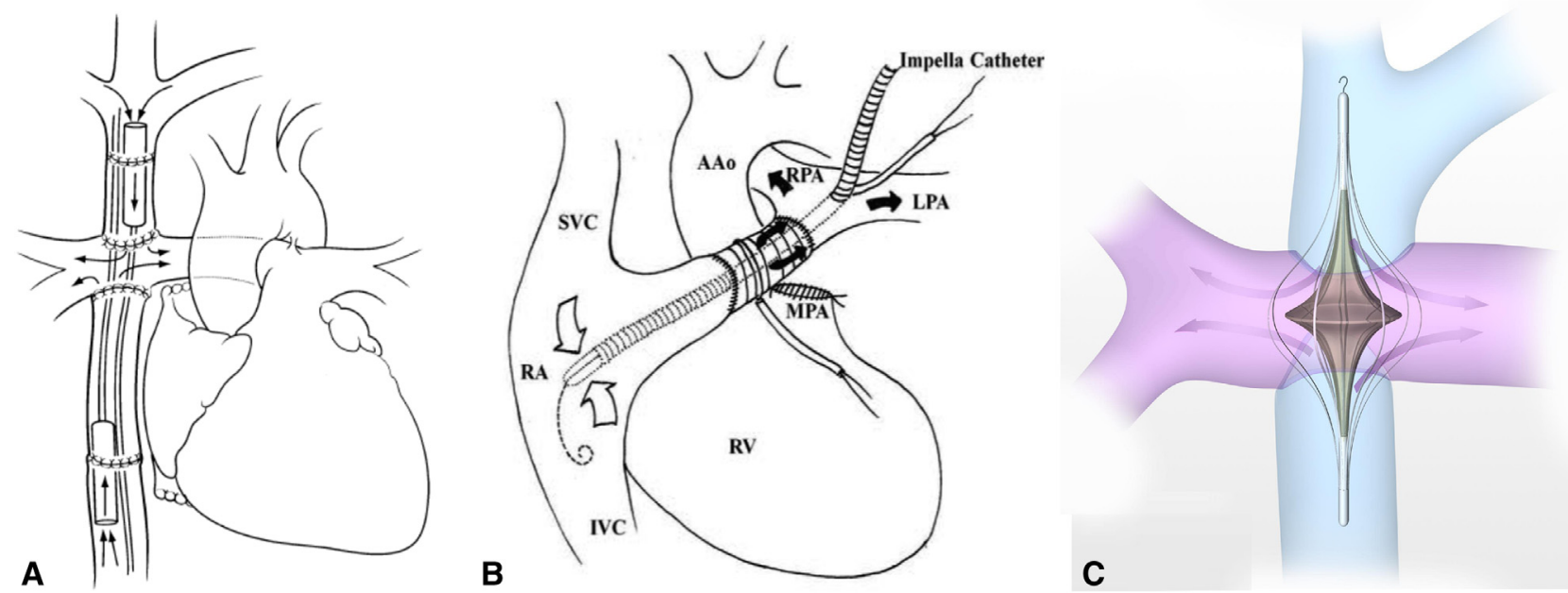

FIGURE 3. Intravascular mechanical Fontan assists. A, Axial flow device. Two devices are used, 1 each in the SVC and IVC ${ }^{33}$ (permission for reprint obtained from Elsevier). B, Catheter-based device is placed in an acute model of atriopulmonary Fontan connection ${ }^{34}$ (permission for reprint obtained from Wolters Kluwer Health, Inc). C, von Karman impeller pump is placed in the center of the TCPC ${ }^{35}$ (permission for reprint obtained from Elsevier). The rotating disc radially displaces fluid and reduces power loss. AAo, Ascending aorta; RPA, right pulmonary artery; SVC, superior vena cava; $M P A$, main pulmonary artery; $L P A$, left pulmonary artery; $R A$, right atrium; $R V$, right ventricle; $I V C$, inferior vena cava.

devices in idealized Fontan models ${ }^{36}$ and patient-specific anatomy rendered from imaging data. ${ }^{37}$ Several other studies have investigated the use of novel axial flow devices as subpulmonary assists to the Fontan circulation in both computational fluid dynamics or mock circulation flowloop models. ${ }^{38-41}$ In addition to axial flow devices, others have tested novel or prototype pulsatile and centrifugal ventricular assist devices (VADs) in a mock Fontan circuit. $^{42}$

Several groups have studied the applicability of clinically available VADs to augment flows within the TCPC. ${ }^{43-46}$ Notably, VADs are nearly all designed for systemic arterial support, and some modification of the commercially available devices has often been necessary to allow them to operate in low pressure systems. ${ }^{46}$ Derk and colleagues ${ }^{43}$ inserted the Jarvik 2000 (Jarvik Heart, Inc, New York, NY) axial flow pump between the systemic venous return and the PAs in an acute pig Fontan model. Both the SVC and IVC provided inflow to the device with outflow connected to the MPA. After completing the Fontan circuit, the animals experienced systemic venous hypertension and an acute decrease in CO. However, activation of the device restored normal physiologic parameters. Another group found similar results with TCPC assist from the HeartMate II (Thoratec Corp, Pleasanton, Calif) in an acute sheep model. ${ }^{44,45}$

A different study also used the Jarvik 2000 in a "T-shaped" TCPC sheep model. ${ }^{46}$ The "T" TCPC configuration was accomplished by connecting the IVC to the SVC with an ePTFE tube and attaching a second conduit (in which the VAD was placed) perpendicularly to the downstream end that was connected to the PA trunk. The investigators generated approximately 2 to $3 \mathrm{~L} / \mathrm{min}$ flows in the modified TCPC. The CVP in the supported group resembled baseline conditions with a mild increase in pulmonary pressures 3 hours into the experiment. A recent study evaluated the efficacy of the HeartWare CircuLite (Framingham, Mass) to augment subpulmonary flows in an in vitro mock Fontan circulation. The VAD was tested in 3 scenarios within the TCPC but was unable to achieve the authors' goals for hemodynamic assistance in any of the configurations. ${ }^{47}$

A recent study by Pekkan and colleagues ${ }^{48}$ described use of an "integrated aortic turbine venous assist system" for augmentation of pulmonary arterial flow in patients with Fontan circulation. The group's novel design uses systemic arterial blood pressure as the driving force of the device, which would obviate the need for an external power source and driveline. The high systemic pressure head drives the blood turbine to power a pump impeller that supplies the high-flow and low-pressure venous circulation. The investigators tested the device in a mock flow loop of several different Fontan circulation scenarios. This powerful proof-of-concept study was limited by several prototype inefficiencies, and in experiments an aortic steal of $1.0 \mathrm{~L} / \mathrm{min}$ produced a net pump assist of 2 to $3 \mathrm{~mm} \mathrm{Hg}$ in the subpulmonary circulation. The authors discussed improved design characteristics in a second-generation device with encouraging results in, as yet, unpublished studies. This impressive work showcases the ingenuity and creative approaches investigators are taking to create solutions for patients with Fontan circulation.

Catheter-based VADs have been proposed as a temporary means of supporting failing Fontan circulation. ${ }^{49}$ In an 

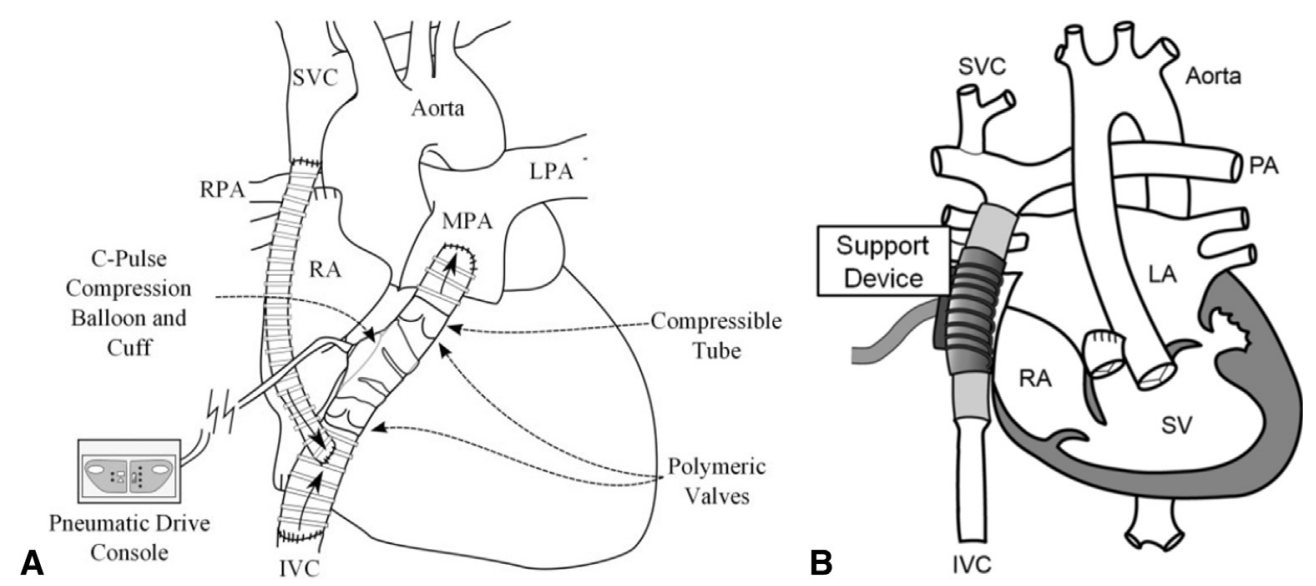

FIGURE 4. Extravascular mechanical Fontan assists. A, Balloon-cuff device attached to a modified Fontan connection scenario in which both caval flows input to the modified connection ${ }^{55}$ (permission for reprint obtained from John Wiley and Sons). B, Sequential compression device designed from multiple shape memory allow rings placed around an extracardiac conduit for an assist scenario ${ }^{56}$ (Permission for reprint obtained from IEEE). SVC, Superior vena cava; $R P A$, right pulmonary artery; $L P A$, left pulmonary artery; $M P A$, main pulmonary artery; $R A$, right atrium; $I V C$, inferior vena cava; $P A$, pulmonary artery; $L A$, left atrium; $S V$, single ventricle.

in vitro mock circuit of the TCPC, Impella devices (Abiomed, Danvers, Mass) were used to characterize the local response of pressures and flows during support. Use of Impella devices improved hemodynamics; however, a barrier separating the inlet and outlet of the device was required to prevent recirculation and provide meaningful work. Additionally, 2 devices were required to avoid systemic venous hypertension in the SVC circuit. A different group tested the Impella system in an acute animal model of atriopulmonary Fontan connection ${ }^{34}$ (Figure 3). Animals not supported by the device quickly experienced cardiovascular collapse. The investigators found recirculation to be a significant issue with device use. However, once a tourniquet was placed between the inflow and outflow of the device preventing recirculation, mean arterial pressure was increased with concomitant decrease in CVP and normalization of mixed venous saturations.

An ingenious solution to circumvent the potential for caval collapse, hemolysis, and obstruction to venous return, Rodefeld and colleagues ${ }^{50}$ designed a viscous impeller pump based on the von Karman pump princi$\mathrm{pl}^{50}$ (Figure 3). The design uses a large, flat disk that is rotated; fluid is drawn in vertical, Y-axis and accelerated outwardly in the radial, $\mathrm{X}$-axis direction. Thus, placing the disk in the center of the TCPC may potentially augment blood flow in both pulmonary arteries with a single device. In experiments, a stationary impeller caused an $88 \%$ reduction in blood flow power loss. A $20 \mathrm{~mm} \mathrm{Hg}$ pressure increase in the PAs was generated at approximately $4 \mathrm{~L} / \mathrm{min}$ when surface vanes were incorporated into the impeller design. Although follow-up studies showed hemodynamic advantage of the viscous impeller pump in the in vitro setting, ${ }^{51-53}$ no studies yet describe in vivo support.
In addition to the previously described intravascular mechanical support devices, mechanical devices with extravascular mechanisms have been investigated. Yamada and colleagues ${ }^{54}$ described the potential utility of a temporary pulmonary circulation support device to provide pulsatile, "peristaltic" flow in patients with Fontan circulation who have a TCPC (Figure 4). In a simple mock flow circuit, memory-alloy fibers were wrapped around an ePTFE Fontan conduit and stimulated to "contract" with an electrical current. When contracting fibers in a sequential fashion, the researchers generated a pulse pressure of 3 to $5 \mathrm{~mm} \mathrm{Hg}$. However, neither mean flow rates nor mean pressures experienced significant changes.

In a different extravascular device application, Valdovinos and colleagues ${ }^{55}$ tested the potential of an extra-aortic balloon device to augment pulmonary blood flow in a mock Fontan flow loop (Figure 4). The c-Pulse system (CHF Solutions, Inc., Eden Prairie, Minn.), which is a counter-pulsation device and uses an inflatable ballooncuff, was secured to a polymer conduit flanked by valves in a simulated modified, mock Fontan circulation. Activation of the balloon provided pulsatile and increased PA flow. When the valves were removed, researchers found an increase in IVC pressure that resulted from conduit occlusion and lack of unidirectional flow.

\section{CLINICAL FONTAN CIRCULATION ASSISTANCE}

The use of mechanical support devices in patients with single ventricles is becoming increasingly frequent. ${ }^{57} \mathrm{Clin}-$ ical application of VADs in patients with failing Fontan circulation is almost universally relegated to support of systemic arterial blood flow. ${ }^{58-69}$ At our institution, we used a VAD to facilitate Fontan completion in a patient with Glenn physiology and severe ventricular 
dysfunction. ${ }^{70}$ A recent article demonstrated the promise of temporary, catheter-based VAD support of the failing systemic ventricle. ${ }^{71}$

Several patients with failing Fontan physiology have received simultaneous support of both the pulmonary and systemic arterial circulations (or pseudo "biventricular support") with device therapy including with dual Berlin EXCOR devices (Berlin Heart, Berlin, Germany) or the SynCardia total artificial heart (SynCardia Systems, LLC, Tucson, Ariz) ${ }^{65,72,73}$ A clever strategy to a create a "biventricular-like" like solution for a patient with a failing single ventricle (non-Fontan) used 2 HeartWare HVAD pumps; one was placed in the ventricle in a usual fashion. After closing the atrial communication, a second device was placed in the RA and a modified outflow cannula was anastomosed to the PA. The patient's status improved, and the patient was discharged home to await heart transplantation. ${ }^{74}$

To the authors' knowledge, there is only a solitary published report of mechanical support isolated to pulmonary blood flow in a patient with Fontan circulation. ${ }^{75}$ A 27-year-old patient with tricuspid atresia presented 4 months after Fontan revision with multiorgan dysfunction, a CVP of $30 \mathrm{~mm} \mathrm{Hg}$ but normal ventricular function, and a competent mitral valve. Therefore, surgeons created a capacitance chamber, separated from the PAs, with inflows from IVC and SVC. The capacitance chamber was cannulated for inflow to the Berlin device, and the PA was cannulated for outflow to provide pulsatile, augmented pulmonary blood flow. The patient quickly experienced an improvement in symptoms, and, after 10 days, CVP decreased to less than $8 \mathrm{~mm} \mathrm{Hg}$. Thirteen months after implantation of the device, the patient successfully received a heart transplant. Although only clinically described once, some posit we may be at the dawn of a new clinical paradigm for patients with complex congenital heart disease in whom elective subpulmonary support could become the "fourth stage" of single ventricle palliation. ${ }^{14}$

\section{FONTAN CIRCULATION ASSIST THERAPIES ON THE HORIZON}

Technologic progress in the coming years may enable those born with single ventricle congenital heart disease a better quality of life and longevity. In just more than 40 years, progress from the congenital heart community, including innovations in surgical techniques as well as preoperative and postoperative care, has revolutionized the outlook for patients with single ventricle physiology. Likewise, already sophisticated VAD technology will continue to undergo further development and refinement that may enable use as primary, destination therapy. Use of transcutaneous charging technologies to realize driveline-less, fully implantable VADs ${ }^{76}$ may be particularly relevant for patients with Fontan circulation because the power requirements may be $20 \%$ or less than a traditional left VAD. As previously mentioned, a blood turbine could eliminate the need for a traditional power source and the need for a driveline. ${ }^{48}$ The expected reduction in infectious complications and increased freedom for patients that could result from a driveline-less VAD would be a significant boon for patients with Fontan circulation and may even enable chronic, long-term subpulmonary circulatory support.

The promise of stem cell technology and tissue engineering/regenerative medicine (TERM) may provide an alternative solution to the Fontan dilemma. Several investigators are attempting to apply TERM technologies to advance the care of patients with congenital heart disease. ${ }^{77-79} \mathrm{In}$ an intriguing study, Biermann and colleagues ${ }^{80}$ described attempts to create a "contractile extracardiac Fontan-tunnel" with engineered heart tissue. Further, some investigators, including those in our group, are using TERM technologies with the intent to recapitulate the entire heart, ${ }^{81,82}$ which would obviate the need for a subpulmonary assist device.

Although past attempts for biologically based devices failed, new engineering opportunities are available to create a TERM device with relevant characteristics for subpulmonary Fontan circulation support. Previous biological devices required use of $\mathrm{LD}$ (skeletal muscle), which has intrinsic properties incompatible with older valve technology and unsuitable for use as blood pump. Not only has valve technology improved but also stem cell biology has evolved. Thus, today many cell types are available for use in a TERM device, including cardiomyocytes that can be derived from autologous or allogeneic sources. Moreover, germane cell types can be coupled with bio-matrices with "tunable" mechanical properties, making an intentionally designed TERM device more likely to achieve the specific requirements for use as a subpulmonary assist device. Given the number of component options available, the properties of a TERM device may be tailored to improve compatibility with promising existing valve technology. ${ }^{15,83}$ We believe a subpulmonary assist device that incorporates TERM technologies is the solution with the highest likelihood to achieve chronic support for the Fontan circulation, and we have established a program to generate a novel biological subpulmonary pump.

\section{CONCLUSIONS}

Temporary support of failing Fontan circulation is desirable when the patient is a candidate for cardiac transplantation; however, the "Holy Grail" of subpulmonary Fontan assistance is application of a durable, long-term solution for patients. The report from Pretre and colleagues ${ }^{75}$ confirms mechanical subpulmonary assistance is possible in patients with Fontan circulation. Previously attempted biological and mechanical assist devices possess drawbacks making their use for long-term support less desirable or 
impossible. The putative solution for Fontan cases would incorporate a robust, sustainable, biologically compatible subpulmonary assist device with minimal energy input. The device should be designed to avoid producing a significant clot burden. However, meeting rigorous engineering specifications to create a perfectly nonthrombogenic device may not be entirely necessary because an occurrence of a (small) thromboembolism of the pulmonary capillary bed would likely be better "tolerated" than a systemic/central nervous system embolus. Advances in mechanical VAD technologies or TERM techniques may achieve clinically relevant, meaningful subpulmonary cavopulmonary support. We are hopeful that new and innovative strategies will meet the challenge of overcoming the inevitable sequelae of the Fontan circulation.

\section{Conflict of Interest Statement}

Financial support for this work was provided by the Jack Carter, Jr, Technology Catalyst Fund, Baylor College of Medicine, Houston, Texas. D.A.T. has financial interests in Miromatrix, Inc. I.A. is a consultant and proctor for HeartWare International Inc, and Berlin Heart Inc. C.R.B. has nothing to disclose with regard to commercial support.

\section{References}

1. Fontan F, Baudet E. Surgical repair of tricuspid atresia. Thorax. 1971;26:240-8.

2. Gewillig M, Brown SC. The Fontan circulation after 45 years: update in physiology. Heart. 2016;102:1081-6.

3. d'Udekem Y, Rychik J. Towards the goal of achieving a normal duration and quality of life after Fontan operation: creation of the international Fontan interest group (I-FIG), an international collaborative initiative dedicated to improving outcomes. Int J Cardiol. 2017;245:131-4.

4. Schilling C, Dalziel K, Nunn R, Du Plessis K, Shi WY, Celermajer D, et al. The Fontan epidemic: population projections from the Australia and New Zealand Fontan registry. Int J Cardiol. 2016;219:14-9.

5. Gewillig M. The Fontan circulation. Heart. 2005;91:839-46.

6. Goldberg DJ, Shaddy RE, Ravishankar C, Rychik J. The failing Fontan: etiology, diagnosis and management. Expert Rev Cardiovasc Ther. 2011;9:785-93.

7. Ghanayem NS, Berger S, Tweddell JS. Medical management of the failing Fontan. Pediatr Cardiol. 2007:28:465-71.

8. De Rita F, Crossland D, Griselli M, Hasan A. Management of the failing Fontan. Semin Thorac Cardiovasc Surg Pediatr Card Surg Annu. 2015;18:2-6.

9. Feldt RH, Driscoll DJ, Offord KP, Cha RH, Perrault J, Schaff HV, et al. Proteinlosing enteropathy after the Fontan operation. J Thorac Cardiovasc Surg. 1996; 112:672-80.

10. Mertens L, Hagler DJ, Sauer U, Somerville J, Gewillig M. Protein-losing enteropathy after the Fontan operation: an international multicenter study. PLE study group. J Thorac Cardiovasc Surg. 1998;115:1063-73.

11. Pundi KN, Johnson JN, Dearani JA, Pundi KN, Li Z, Hinck CA, et al. 40-year follow-up after the Fontan operation: Long-term outcomes of 1,052 patients. $J$ Am Coll Cardiol. 2015;66:1700-10.

12. Collins RT II, Fram RY, Tang X, Robbins JM, Sutton MS. Impact of anatomical subtype and medical comorbidities on hospitalizations in adults with single ventricle congenital heart disease. Int J Cardiol. 2013;168:4596-601.

13. Cedars A, Benjamin L, Vyhmeister R, Harris K, Bradley EA, Wadia S, et al. Contemporary hospitalization rate among adults with complex congenital heart disease. World J Pediatr Congenit Heart Surg. 2016;7:334-43.

14. Jaquiss RD, Aziz H. Is four stage management the future of univentricular hearts? destination therapy in the young. Semin Thorac Cardiovasc Surg Pediatr Card Surg Anпu. 2016;19:50-4.
15. Malekzadeh-Milani S, Ladouceur M, Iserin L, Boudjemline Y. Percutaneous valvulation of failing Fontan: rationale, acute effects and follow-up. Arch Cardiovasc Dis. 2014; 107:599-606.

16. de Leval MR, Deanfield JE. Four decades of Fontan palliation. Nat Rev Cardiol. 2010;7:520-7.

17. de Leval MR, Kilner P, Gewillig M, Bull C. Total cavopulmonary connection: a logical alternative to atriopulmonary connection for complex Fontan operations. experimental studies and early clinical experience. J Thorac Cardiovasc Surg. 1988;96:682-95

18. Elder RW, McCabe NM, Hebson C, Veledar E, Romero R, Ford RM, et al. Features of portal hypertension are associated with major adverse events in Fontan patients: the VAST study. Int J Cardiol. 2013;168:3764-9.

19. Pochettino A, Spanta AD, Hammond RL, Anderson DR, Bridges CR Jr, Samet P, et al. Skeletal muscle ventricles for total heart replacement. Ann Surg. 1990;212: 345-52.

20. Voss B, Sack FU, Saggau W, Hagl S, Lange R. Atrial cardiomyoplasty in a Fontan circulation. Eur J Cardiothorac Surg. 2002;21:780-6.

21. Macoviak JA, Stinson EB, Starkey TD, Hansen DE, Cahill PD, Miller DC, et al Myoventriculoplasty and neoventricle myograft cardiac augmentation to establish pulmonary blood flow. preliminary observations and feasibility studies. $J$ Thorac Cardiovasc Surg. 1987;93:212-20.

22. Bridges CR Jr, Hammond RL, Dimeo F, Anderson WA, Stephenson LW. Func tional right-heart replacement with skeletal muscle ventricles. Circulation. 1989;80(5 Pt 2):III183-91.

23. Niinami H, Hooper TL, Hammond RL, Ruggiero R, Pochettino A, Colson M, et al. A new configuration for right ventricular assist with skeletal muscle ventricle. short-term studies. Circulation. 1991;84:2470-5.

24. Niinami H, Hooper TL, Hammond RL, Ruggiero R, Lu H, Spanta AD, et al. Skel etal muscle ventricles in the pulmonary circulation: up to 16 weeks' experience. Ann Thorac Surg. 1992;53:750-7.

25. Morita K, Kurosawa H, Nomura K, Ko Y, Hanai M, Kawada N, et al. Right ventricular dynamic cardiomyoplasty for the univentricular heart with pulmonary hypertension. Jpn J Thorac Cardiovasc Surg. 2001;49:207-15.

26. Chachques JC, Grandjean P, Serraf A, Latremouille C, Jebara VA, Ponzio O, et al Atrial cardiomyoplasty after Fontan-type procedures. Circulation. 1990;82: IV183-9.

27. Corno AF, Vergara C, Subramanian C, Johnson RA, Passerini T, Veneziani A et al. Assisted Fontan procedure: animal and in vitro models and computational fluid dynamics study. Interact Cardiovasc Thorac Surg. 2010;10:679-84.

28. Monnet E, Orton EC, Jacobs G, Metelman L. Fluoroscopic determination of latissimus dorsi muscle shortening fraction after dynamic cardiomyoplasty. Pacing Clin Electrophysiol. 1998;21:1741-6.

29. Salmons S. Cardiac assistance from skeletal muscle: should we be downhearted? Ann Thorac Surg. 2005;79:1101-3.

30. Rose EA, Gelijns AC, Moskowitz AJ, Heitjan DF, Stevenson LW, Dembitsky W, et al. Long-term use of a left ventricular assist device for end-stage heart failure. N Engl J Med. 2001;345:1435-43.

31. Slaughter MS, Rogers JG, Milano CA, Russell SD, Conte JV, Feldman D, et al. Advanced heart failure treated with continuous-flow left ventricular assist device. N Engl J Med. 2009;361:2241-51.

32. Waqas M, Cowger JA. Role of durable mechanical circulatory support for the management of advanced heart failure. Heart Fail Clin. 2016;12:399-409.

33. Rodefeld MD, Boyd JH, Myers CD, LaLone BJ, Bezruczko AJ, Potter AW, et al. Cavopulmonary assist: circulatory support for the univentricular Fontan circulation. Ann Thorac Surg. 2003;76:1911-6.

34. Zhu J, Kato H, Fu YY, Zhao L, Foreman C, Davey L, et al. Cavopulmonary sup port with a microaxial pump for the failing Fontan physiology. ASAIO J. 2015;61: 49-54.

35. Rodefeld MD, Frankel SH, Giridharan GA. Cavopulmonary assist: (em)powering the univentricular Fontan circulation. Semin Thorac Cardiovasc Surg Pediatr Card Surg Annu. 2011;14:45-54.

36. Bhavsar SS, Kapadia JY, Chopski SG, Throckmorton AL. Intravascular mechanical cavopulmonary assistance for patients with failing Fontan physiology. Artif Organs. 2009;33:977-87.

37. Throckmorton AL, Carr JP, Tahir SA, Tate R, Downs EA, Bhavsar SS, et al. Mechanical cavopulmonary assistance of a patient-specific Fontan physiology: numerical simulations, lumped parameter modeling, and suction experiments Artif Organs. 2011;35:1036-47.

38. Lacour-Gayet FG, Lanning CJ, Stoica S, Wang R, Rech BA, Goldberg S, et al. An artificial right ventricle for failing Fontan: In vitro and computational study. Ann Thorac Surg. 2009;88:170-6. 
39. Di Molfetta A, Amodeo A, Fresiello L, Trivella MG, Iacobelli R, Pilati M, et al. Simulation of ventricular, cavo-pulmonary, and biventricular ventricular assist devices in failing Fontan. Artif Organs. 2015;39:550-8.

40. Pekkan K, Frakes D, De Zelicourt D, Lucas CW, Parks WJ, Yoganathan AP. Coupling pediatric ventricle assist devices to the Fontan circulation: simulations with a lumped-parameter model. ASAIO J. 2005;51:618-28.

41. Chopski SG, Rangus OM, Downs EA, Moskowitz WB, Throckmorton AL. Three-dimensional laser flow measurements of a patient-specific Fontan physiology with mechanical circulatory assistance. Artif Organs. 2015;39:E67-78.

42. Dur O, Lara M, Arnold D, Vandenberghe S, Keller BB, DeGroff C, et al. Pulsatile in vitro simulation of the pediatric univentricular circulation for evaluation of cardiopulmonary assist scenarios. Artif Organs. 2009;33:967-76.

43. Derk G, Laks H, Biniwale R, Patel S, De LaCruz K, Mazor E, et al. Novel techniques of mechanical circulatory support for the right heart and Fontan circulation. Int J Cardiol. 2014;176:828-32.

44. Riemer RK, Amir G, Reichenbach SH, Reinhartz O. Mechanical support of total cavopulmonary connection with an axial flow pump. J Thorac Cardiovasc Surg. 2005;130:351-4.

45. Tsuda S, Sasaki T, Maeda K, Riemer RK, Reichenbach SH, Reinhartz O. Recovery during mid-term mechanical support of Fontan circulation in sheep. ASAIO J. 2009;55:406-11.

46. Gandolfo F, Brancaccio G, Donatiello S, Filippelli S, Perri G, Iannace E, et al. Mechanically assisted total cavopulmonary connection with an axial flow pump: computational and in vivo study. Artif Organs. 2016;40:43-9.

47. Tree M, Trusty PM, Slesnick TC, Yoganathan A, Deshpande S, Maher K. In vitro examination of the HeartWare CircuLite ventricular assist device in the Fontan connection. ASAIO J. 2017;63:482-9.

48. Pekkan K, Aka IB, Tutsak E, Emek E, Balim H, Lazoglu I, et al. In vitro validation of a self-driving aortic-turbine venous-assist device for Fontan patients. $J$ Thorac Cardiovasc Surg. 2018;156:292-301.e7.

49. Haggerty CM, Fynn-Thompson F, McElhinney DB, Valente AM, Saikrishnan N, Del Nido PJ, et al. Experimental and numeric investigation of Impella pumps as cavopulmonary assistance for a failing Fontan. J Thorac Cardiovasc Surg. 2012; 144:563-9.

50. Rodefeld MD, Coats B, Fisher T, Giridharan GA, Chen J, Brown JW, et al. Cavopulmonary assist for the univentricular Fontan circulation: von Karman viscous impeller pump. J Thorac Cardiovasc Surg. 2010;140:529-36.

51. Kerlo AM, Delorme YT, Xu D, Frankel SH, Giridharan GA, Rodefeld MD, et al. Experimental characterization of powered Fontan hemodynamics in an idealized total cavopulmonary connection model. Exp Fluids. 2013;54:1-18.

52. Iliff B, Kerlo A, Chen J, Rodefeld M, Goergen C. In vitro ultrasound measurements of powered and unpowered total cavopulmonary connection. Austin J Biomed Eng. 2014;1:1026

53. Giridharan GA, Koenig SC, Kennington J, Sobieski MA, Chen J, Frankel SH, et al. Performance evaluation of a pediatric viscous impeller pump for Fontan cavopulmonary assist. J Thorac Cardiovasc Surg. 2013;145:249-57.

54. Yamada A, Shiraishi Y, Miura H, Hashem HM, Tsuboko Y, Yamagishi M, et al. Development of a thermodynamic control system for the Fontan circulation pulsation device using shape memory alloy fibers. J Artif Organs. 2015;18:199-205.

55. Valdovinos J, Shkolyar E, Carman GP, Levi DS. In vitro evaluation of an external compression device for Fontan mechanical assistance. Artif Organs. 2014;38: 199-207.

56. Yamada A, Shiraishi Y, Miura H, Yambe T, Omran MH, Shiga T, et al. Peristaltic hemodynamics of a new pediatric circulatory assist system for Fontan circulation using shape memory alloy fibers. Conf Proc IEEE Eng Med Biol Soc. 2013;2013: 683-6.

57. Buratto E, Shi WY, Ye XT, Konstantinov IE. Ventricular assist devices for the failing univentricular circulation. Expert Rev Med Devices. 2017;14:449-59.

58. Sadeghi AM, Marelli D, Talamo M, Fazio D, Laks H. Short-term bridge to transplant using the BVS 5000 in a 22-kg child. Ann Thorac Surg. 2000;70:2151-3.

59. Frazier OH, Gregoric ID, Messner GN. Total circulatory support with an LVAD in an adolescent with a previous Fontan procedure. Tex Heart Inst J. 2005;32:402-4.

60. Morales DL, Adachi I, Heinle JS, Fraser CD Jr. A new era: use of an intracorporeal systemic ventricular assist device to support a patient with a failing Fontan circulation. J Thorac Cardiovasc Surg. 2011;142:e138-40.

61. Niebler RA, Ghanayem NS, Shah TK, De La Rosa Bobke A, Zangwill S, Brosig C, et al. Use of a HeartWare ventricular assist device in a patient with failed Fontan circulation. Ann Thorac Surg. 2014;97:e115-6.

62. Calvaruso DF, Ocello S, Salviato N, Guardì D, Petruccelli DF, Rubino A, et al. Implantation of a Berlin heart as single ventricle by-pass on Fontan circulation in univentricular heart failure. ASAIO J. 2007;53:e1-2.
63. Hoganson DM, Boston US, Gazit AZ, Canter CE, Eghtesady P. Successful bridge through transplantation with Berlin heart ventricular assist device in a child with failing Fontan. Ann Thorac Surg. 2015;99:707-9.

64. Halaweish I, Ohye RG, Si MS. Berlin heart ventricular assist device as a longterm bridge to transplantation in a Fontan patient with failing single ventricle. $\mathrm{Pe}$ diatr Transplant. 2015;19:E193-5.

65. Weinstein S, Bello R, Pizarro C, Fynn-Thompson F, Kirklin J, Guleserian K, et al. The use of the Berlin Heart EXCOR in patients with functional single ventricle. $J$ Thorac Cardiovasc Surg. 2014; 147:697-705.

66. Arnaoutakis GJ, Blitzer D, Fuller S, Eckhauser AW, Montenegro LM, Rossano JW, et al. Mechanical circulatory support as bridge to transplantation for the failing single ventricle. Ann Thorac Surg. 2017;103:193-7.

67. Imielski BR, Niebler RA, Kindel SJ, Woods RK. HeartWare ventricular assist device implantation in patients with Fontan physiology. Artif Organs. 2017;41: 40-6.

68. Cardarelli MG, Salim M, Love J, Simone S, Tumulty J, Conway D, et al. Berlin heart as a bridge to recovery for a failing Fontan. Ann Thorac Surg. 2009;87: 943-6.

69. Mackling T, Shah T, Dimas V, Guleserian K, Sharma M, Forbess J, et al. Management of single-ventricle patients with Berlin Heart EXCOR ventricular assist device: single-center experience. Artif Organs. 2012;36:555-9.

70. Adachi I, Williams E, Jeewa A, Elias B, McKenzie ED. Mechanically assisted Fontan completion: a new approach for the failing Glenn circulation due to isolated ventricular dysfunction. J Heart Lung Transplant. 2016;35: 1380-1.

71. Morray BH, Dimas VV, Lim S, Balzer DT, Parekh DR, Van Mieghem NM, et al. Circulatory support using the Impella device in Fontan patients with systemic ventricular dysfunction: a multicenter experience. Catheter Cardiovasc Interv. 2017;90:118-23.

72. Valeske K, Yerebakan C, Mueller M, Akintuerk H. Urgent implantation of the BERLIN heart Excor biventricular assist device as a total artificial heart in a patient with single ventricle circulation. J Thorac Cardiovasc Surg. 2014;147: $1712-4$.

73. Rossano JW, Goldberg DJ, Fuller S, Ravishankar C, Montenegro LM, Gaynor JW. Successful use of the total artificial heart in the failing Fontan circulation. Ann Thorac Surg. 2014;97:1438-40.

74. Ovroutski S, Miera O, Krabatsch T, Berger F, Photiadis J, Potapov E. Two pumps for single ventricle: mechanical support for establishment of biventricular circulation. Ann Thorac Surg. 2017;104:e143-5.

75. Pretre R, Haussler A, Bettex D, Genoni M. Right-sided univentricular cardiac assistance in a failing Fontan circulation. Ann Thorac Surg. 2008;86:1018-20.

76. Waters BH, Sample AP, Bonde P, Smith JR. Powering a ventricular assist device (VAD) with the free-range resonant electrical energy delivery (FREE-D) system. Proc IEEE. 2012;100:138-49.

77. Zimmermann WH, Cesnjevar R. Cardiac tissue engineering: implications for pe diatric heart surgery. Pediatr Cardiol. 2009;30:716-23.

78. Shinoka T, Shum-Tim D, Ma PX, Tanel RE, Isogai N, Langer R, et al. Creation of viable pulmonary artery autografts through tissue engineering. J Thorac Cardiovasc Surg. 1998;115:536-46.

79. Shin'oka T, Matsumura G, Hibino N, Naito Y, Watanabe M, Konuma T, et al. Midterm clinical result of tissue-engineered vascular autografts seeded with autologous bone marrow cells. J Thorac Cardiovasc Surg. 2005;129: 1330-8.

80. Biermann D, Eder A, Arndt F, Seoudy H, Reichenspurner H, Mir T, et al. Towards a tissue-engineered contractile Fontan -conduit: The fate of cardiac myocytes in the subpulmonary circulation. PLoS One. 2016;11:e0166963.

81. Ott HC, Matthiesen TS, Goh SK, Black LD, Kren SM, Netoff TI, et al. Perfusion-decellularized matrix: using nature's platform to engineer a bioartificial heart. Nat Med. 2008;14:213-21.

82. Guyette JP, Charest JM, Mills RW, Jank BJ, Moser PT, Gilpin SE, et al. Bioengineering human myocardium on native extracellular matrix. Circ Res. 2016; 118:56-72.

83. Vukicevic M, Conover T, Jaeggli M, Zhou J, Pennati G, Hsia TY, et al. Control of respiration-driven retrograde flow in the subdiaphragmatic venous return of the Fontan circulation. ASAIO J. 2014;60:391-9.

Key Words: circulatory assist device, failing fontan, fontan circulation, subpulmonary assist, total cavopulmonary connection 